\section{Menstrual changes with antipsychotic drugs}

SIR: Menstruation could be termed a life event for women. Although a minor irritant to some, it becomes a major issue to others. It is surprising that the issue of menstruation in chronic schizophrenic women has been little studied.

It is known that neuroleptics can cause amenorrhoea and this is now accepted as a side effect, yet many clinicians choose not to enquire about it. It may, however, be of vital importance to a young married schizophrenic woman expected to remain on depot neuroleptic medication for an undefined number of years.

It is also known that psychotic patients may experience amenorrhoea regardless of whether or not they are on neuroleptic medication for their psychosis. The incidence is higher for those women on neuroleptics but the physiological basis for this is as yet unknown. Ghadirian et al (1982) demonstrated that $91 \%$ of their schizophrenic patients experienced menstrual changes but the researchers were unable to specify the nature and quality of the changes. Meltzer \& Fang (1976), in a cohort of women on neuroleptics, showed that nearly all had a rise in prolactin as early as three days after commencing neuroleptics, which is presumed to be the cause of the amenorrhoea. In a different study, the same authors found that up to $50 \%$ of women on neuroleptics can be expected to become amenorrhoeic.

As part of a larger project, we studied the prevalence of amenorrhoea in a group of 36 chronic schizophrenic women. All patients were already on depot neuroleptics and all fulfilled DSM-III-R diagnostic criteria. We found that over a third of women on depot neuroleptics had menstrual irregularities including amenorrhoea. Our sample ranged in age from 21 to 44 years. Seven women were receiving hormonal contraceptive treatment, and 29 women were not. Of this latter group of 29 women, $4(13 \%)$ were amenorrhoeic, $6(21 \%)$ had irregular menstrual periods and $19(66 \%)$ had regular periods.

Our findings add to the scant literature on the subject. There appears to be a significant proportion of women who experience menstrual changes while on depot neuroleptic medication. Further to the effect that this has on reproductive capacity, there may also be implications with regard to the changing hormonal environment and the severity of psychotic symptoms (Berlin et al, 1982; Clare, 1983).

Berlin, F. S., Bergey, G. K. \& Money, M. (1982) Periodic psychosis of puberty. A case report. American Journal of Psychiatry. $139,119-120$.
Clare, A. W. (1983) The relationship between psychopathology and the menstrual cycle. Women and Health, 8, 125-136.

Ghadirian, A. M., Chovinard, G. \& Annable, L. (1982) Sexual dysfunction and plasma prolactin levels in neuroleptic treated schizophrenic outpatients. Journal of Nervous and Mental Disease, 170, 463-467.

MeltZER, H. Y. \& FANG, V. S. (1976) The effect of neuroleptics on serum prolactin in schizophrenic patients. Archives of General Psychiatry, 33, 279-286.

Newtown Hospital

K. H. Gingell

Newtown Road

Worcester

Kidderminster General Hospital

Worcestershire

J. S. DARLEY

All Saints Hospital

Lodge Road

Winson Green

Birmingham B18

\section{The Unconscious Before Freud}

SIR: I was delighted to see Lancelot Law Whyte's The Unconscious Before Freud reviewed under "Books Reconsidered" (Journal, September 1992, 161, 430432). I have always been a fan of this book and often referred to it, so I was surprised to see Tim Rogers say that "it is not cited by many of the standard works on dynamic psychotherapy". Dennis Brown and I (1991) in our joint Introduction to Psychotherapy refer to it several times. I also referred to it in a Freud Memorial Lecture (Pedder, 1989) for exactly the reasons that Rogers gives, to place psychoanalysis in the proper context of the development of Western thought over several centuries, and to show that psychoanalytic ideas about conflict have a long prehistory. Freud's contribution was to address these ideas to a medical context in a way that stuck.

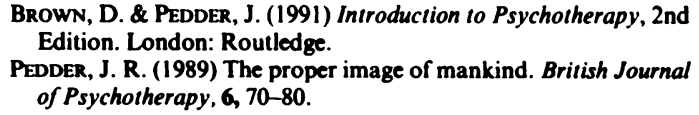

BROWN, D. \& PEDDER, J. (1991) Introduction to Psychotherapy, 2nd Edition. London: Routledge.

PEDDER, J. R. (1989) The proper image of mankind. British Journal of Psychotherapy, 6, 70-80.

Psychotherapy Unit

Jonathan PedDer

Maudsley Hospital

Denmark Hill

London SES 8 AZ

\section{Self-poisoning and general elections}

SIR: While auditing deliberate self-poisoning (DSP) in Nottingham, I was interested to find a significant fall in cases immediately following the result of the 
1992 General Election. After the announcement of a Conservative victory rates fell, with three cases presenting during this post-election weekend compared with a weekend average of $13(99 \%$ confidence limits; 3.53-22.08). Masterson \& Platt (1989) have previously demonstrated an association between British general elections and parasuicide. In a traditionally Labour voting area, the victories of a Conservative Government in 1970, 1979, 1983 and 1987 were met with an increased rate of parasuicide, while the rate fell following the election of a Labour Government in 1974.

In 1992 the country re-elected a Conservative Government. Nottingham had strongly supported Labour. The result was presumably disappointing for the majority, and in contrast to the findings of Masterton \& Platt there were fewer cases of DSP. The two observations may not be comparable because the 'effects' were demonstrated over different time scales and Masterton \& Platt made no comment on immediate effects.

We have speculated as to the reasons behind the Nottingham phenomenon. We wonder if the fall in our rates of DSP reflects relief that at long last the electioneering was over. I would be interested to hear whether other centres observed similar short-term changes in presentations of self-poisoning cases following the 1992 General Election.

Masterton, G. \& Platt, S. (1989) Parasuicide and general elections. British Medical Journal, 298, 803-804.

Department of Psychiatry

Mark Steels

University Hospital

Queen's Medical Centre

Nottingham NG7 2UH

\section{Tattoed female psychiatric patients}

SIR: While tattooing among women is becomingly increasingly fashionable (Mercer \& Davies, 1991) there is little research on the topic. Females in Borstal who were heavily tattooed were more criminal and aggressive in their attitudes and behaviour compared with less heavily tattooed or non-tattooed inmates (Taylor, 1968) but there is no research on female psychiatric patients. It is known that tattooed male psychiatric patients are more likely to have a diagnosis of personality disorder (Gittleson et al, 1969) and an association has also been found with men who harm themselves (Virkkunen, 1976). We examined female acute psychiatric in-patients and day patients in Sheffield. Four had tattoos and all agreed to be interviewed.
Case reports. Patient $\mathrm{A}$ was a 21-year-old with a diagnosis of borderline personality disorder and a history of repeated deliberate self-harm. She had a professional tattoo at the top of her right arm which had been carried out when she was intoxicated in the company of friends at the age of 17. The tattoo was of a panther head baring its teeth. She disliked the tattoo which she wanted to have removed, and kept it covered most of the time. She had been sexually abused from the age of 3 to 6 by her father and stepbrother.

Patient $B$ was a 43-year-old with a diagnosis of borderline personality disorder, alcohol dependency and major affective disorder. She had had multiple admissions with depressive episodes, for detoxification, and following episodes of deliberate self-harm. She had four tattoos, two professional and two that she had done herself. All four were done in her early 20 s while intoxicated with friends and were on her forearms. She had a mixed reaction to the tattoos. She disliked the two professional tattoos, one which was a heart with an arrow through it and the other which coupled her name with that of a former patient. However the two amateur tattoos which were of her mother's name and the names of her three sons gave her comfort at times. She gave a history of being sexually abused between the ages of 5 and 15 by an uncle.

Patient $C$ was a 38-year-old with a diagnosis of borderline personality disorder. She had a long history of repeated deliberate self-harm. She had had two tattoos, one of a pin saint on the right upper arm and one of a man's name on the left lower arm. They were amateur tattoos done by her peers when she was 12 years old. She was ashamed of them and had them removed at the age of 18 leaving a visible scar. She gave a history of having been sexually abused by her father from the age of 10 until he had died when she was 35 .

Patient D was a 27-year-old with a diagnosis of borderline personality disorder and alcohol dependency. She had a history of self-mutilation. She had three amateur tattoos of male names on her forearms done by herself at the age of 17 while intoxicated in the company of friends. She now expresses indifference towards the tattoos. She gave a history of sexual abuse between the ages of 6 and 12 by her stepfather.

Although sexual abuse is common among psychiatric patients it is interesting that all four tattooed patients had been sexually abused. There are several explanations for tattooing. One is the concept of the 'exoskeletal defence' (Popplestone, 1963) suggesting that people with tattoos expect to be attacked and therefore use tattoos as a stereotyped display or symbol of physical strength and psychological aggressiveness. Another concept is that tattoos and other forms of self-mutilation are a way of showing a negative attitude and violence towards oneself. Both explanations could apply to sexual abuse victims. More research needs to be undertaken on a larger controlled sample to investigate whether a correlation exists. Mercer \& Davies (1991) posed the question of whether tattoo removal should be provided by a cash-limited health service. If tattoos 